Article

\title{
How Much Is One Life Worth? The Right to Equity Healthcare for Improving Older Patients' Health Infected by COVID-19
}

\author{
Guiomar Merodio $^{1}$, Mimar Ramis-Salas ${ }^{2}(\mathbb{D})$, Diana Valero ${ }^{1}(\mathbb{D})$ and Adriana Aubert ${ }^{2, *(\mathbb{C})}$ \\ 1 Department of Education, Nebrija University, Santa Cruz de Marcenado, 27, 28015 Madrid, Spain; \\ gmerodio@nebrija.es (G.M.); dvalero@nebrija.es (D.V.) \\ 2 Department of Sociology, University of Barcelona, Avda. Diagonal, 690, 08034 Barcelona, Spain; \\ mimarramis@ub.edu \\ * Correspondence: adriana.aubert@ub.edu; Tel.: +34-934-035-099
}

Received: 21 July 2020; Accepted: 20 August 2020; Published: 23 August 2020

\begin{abstract}
Ageism has a tremendous negative impact on elderly persons and society. Discrimination against the elderly is a driver of health and social inequalities. The COVID-19 pandemic has posed new social and health challenges regarding resource scarcity and shortfalls. Under these difficult circumstances, discourses excluding, and discrimination against, older people have aroused. This article gathers evidence on hospital healthcare experiences of older people infected by COVID-19 during the pandemic outbreak in Spain and it analyzes elements that have positively influenced older patients' perceived health and well-being. We conducted nine qualitative in-depth interviews in Madrid - one of the regions of Spain most affected by COVID-19-with older people that were hospitalized and recovered from COVID-19, family members of old patients infected with COVID-19, and nurses that attended infected older patients. Findings show the challenging experiences faced by older people who were hospitalized due to COVID-19, on the one hand, and the relevance of transformative aspects related to family relationships, solidarity actions, and humanized care that overcame age discrimination, favoring social and equity healthcare for the elderly on the other hand.
\end{abstract}

Keywords: ageism; equity healthcare; COVID-19; elderly people; human rights

\section{Introduction}

Worldwide, older persons are the group most affected by COVID-19 in both morbidity and mortality. In Spain, $87 \%$ of deaths were patients over 70 years old. Men, older patients, and patients with underlying diseases and risk factors are more represented as severity increases [1]. Among people hospitalized for COVID-19, 44.7\% are people over 80 years of age, although this percentage drops to just $0.8 \%$ in the case of those admitted to Intensive Care Units (ICU). The Community of Madrid has been the epicenter of the COVID-19 epidemic in Spain. Madrid is the most affected region with 69,804 registered cases of people infected (28.8\% of infected in the country). Although figures are in constant revision, so far the Community of Madrid has the highest number of deaths-8691 (32\% of the country's total) - and it is the second region with the highest death rate in Spain per 100,000 inhabitants (data updated on 23 May 2020 from the Spanish Ministry of Health). Older persons are at higher risk of serious complications due to COVID-19, and they are particularly vulnerable at nursing homes. At least 5975 elderly residents in nursing homes in the Community of Madrid have died of coronavirus or related symptoms. Of the deceased patients who lived in residences for the elderly, only 500 died in hospitals, which means that $91.6 \%$ of elderly residents who died due to COVID-19 did so at their residences and not at hospitals. 
Thanks to leaks to the press and complaints from family members [2], it has recently come to light that during the hardest moments of the pandemic, in different regions of Spain, health departments issued action guidelines that did not comply with international ethical and scientific standards. These guidelines have been denounced for using discriminatory criteria such as age or disability to exclude patients infected with COVID-19 from receiving hospital care or to limit access to healthcare that could have promoted greater recovery for them. In the Community of Madrid, the Department of Health issued a protocol indicating that patients residing in nursing homes cannot be cared for in hospitals if they are not physically independent or have a mild dependency, or if they have an intellectual disability. These criteria were also indicated for home care of the elderly. Unfairly, this discrimination did not occur for some older patients with private health insurance who were cared for in private hospitals. Similar guidelines were issued in other Spanish regions such as Galicia, Aragon, and Catalonia, and even in the UK [3]. During the pandemic, in Italy, the Società Italiana di Anestesia, Analgesia, Rianimazione e Terapia Intensiva (SIAARTI; Italian Society of Anesthesia, Analgesia, and Intensive Care) published a document with clinical ethics recommendations in which "age" was suggested as a criterion to be considered in a scenario of "extremely scarce" resources [4]. Spanish guidelines have not been transparent, neither have they been public. The Catalan Health Services issued an internal circular on February 24 recommending hospitals not to admit patients over 80 years of age to Intensive Care Units. This generated a great deal of controversy and social denouncement, including an online signature campaign (https://www.change.org/p/generalitat-de-catalunya-las-personas-mayores-tambi\%C3\% A9n-tienen-derecho-a-la-salud) that got over a thousand signatures in a few days. Finally, the Catalan Ministry had to withdraw the internal guideline. The relatives of the victims, elderly patients who died from COVID-19 without receiving the healthcare that would have given them a chance to live, denounced that their relatives had died in an unworthy manner. Three thousand, two hundred victims' relatives have filed a complaint against the Spanish government (https://www.publico.es/politica/ mas-3-200-familias-fallecidos-querellan-sanchez-y-gobierno-homicidio-imprudente.html). This is in line with the response that in recent years has come from citizens who have taken shape in political alternatives, and who have been very critical of the type of democracies that we find in today's Europe [5]. These protocols infringed the right to health equity for all. Elderly people infected by COVID-19 are entitled to quality healthcare regardless of their physical or mental condition, or where they live. Age as exclusion criterion is unethical and violates anti-discrimination laws [6]. Moreover, excluding groups of people for receiving treatment increases the effect of an outbreak, impacting the access to diagnostic testing and treatment [7], and so these protocols can not only have consequences for those directly affected, but also health implications for society.

At the height of the pandemic, Spanish hospitals faced resource scarcity and shortfalls in equipment and personnel. They were overstretched and had to deploy other resources, such as installing a field hospital in Madrid with 5000 beds and seven medicalized hotels. The pandemic has pushed the health system to its limits, raising important challenges such as the allocation of resources. These issues are important to deal with by avoiding unfair discrimination in the population's access to health and by being based on the principle of health equity and justice. The World Health Organization (WHO) defines equity in health as "the absence of unfair and avoidable or remediable differences in health among population groups defined socially, economically, demographically or geographically" [8] (WHO, 2017). On 1st April 2020, the AGE Platform Europe launched a report sharing their alarm regarding COVID-19 and human rights concerns for older persons, expressing that older persons have the same rights as others and must be equally protected during the pandemic. They have the right to life-saving interventions and to receive the highest attainable standard of health. Age can never be a criterion for medical triage, and decision-making must be based on medical needs, scientific evidence, and ethical principles [9]. UN experts have also expressed in this way the demand for a better protection of older persons during the COVID-19 pandemic [10,11]. 


\section{The Negative Impact of Ageism on Health}

There are many studies on structural ageism and its consequences. A recent systematic review points out that ageism has a negative impact on older adults' health, such as reducing longevity and producing depression; it is based on implicit biases and social inequities, and it intersects with other discriminations such as racism [12]. Ageism can be considered a social determinant of health [13]. It also has an economic cost on health [14]. Stereotypes and age discrimination can affect decisions regarding prioritizing healthcare in pandemic emergencies [6], as has been denounced in different regions of Spain.

Even though older people are generally those most at risk for disease, chronic illnesses, disability, and needing permanent quality healthcare, previous studies have also reported that hospitalized older people do not always receive the compassionate care that they need, and that they can suffer a lack of compassion in their care [15]. Regarding frequency and quality of staff and older patient interactions, a study conducted in six UK hospitals observed that $40 \%$ of older patients had at least one negative interaction, and that $10 \%$ of all social interactions between staff-patient were negative. On the other hand, having visitors present was associated with reduced odds of negative interactions [16]. Summarizing evidence from other studies on older people's and relatives' experiences in acute care settings points out the importance that older patients give to relational aspects of care. The negative feelings, anxiety, and fear that older patients may feel are offset by positive relationship experiences described as feeling part of the community, including their relatives, maintaining connections with family and social networks, or feeling that the staff connect with them and that they are included in medical explanations and decision-making [17]. Patient engagement results in the improvement of care and better health outcomes, promoting the sustainability of health systems [18]. With regards to what older persons associate with quality of life and health from a person-centered approach, it has been found that social relationships, closeness, and feeling supported by others, particularly by their family and friends, are very important for feeling included in society [19]. Care is a fundamental social relationship in which a multitude of agents and dimensions intervene to promote the integral recovery of patients, as well as for increasing their quality of life. In recent years, some initiatives and training programs have been developed to deliver compassionate care for elderly people in hospitals. Under a compassionate care approach, patients are perceived as people worthy of dignity with individual needs and desires [17]. Complementarily, a person-centered approach is based on the principle that people should be at the center of decisions; therefore, care and health support should take into account people's concerns [19].

The pandemic caused by COVID-19 is the greatest challenge we have faced since World War II [20]. Healthcare systems are responding to the COVID-19 epidemic increasing their productivity by adopting organizational models close to the paradigm of hospitals as "health factories" [21]. In this context of health emergency, age discrimination has emerged as a barrier to equity care and as a possible driver to health and social inequalities [22,23]. Structural ageism and measures taken by local governments impact the human rights of older persons. They can also affect individual ageism in overwhelming contexts where the lack of resources and capacity can affect the ability of hospital infrastructure to care for elderly patients. However, under this complex and unprecedented situation, there are also successful cases of humanized and equity healthcare for elderly people infected by COVID-19. Governments and society in general are increasingly demanding that science provides a relevant social impact that is for the benefit of the entire society, without discrimination of any group. In times of crisis such as the current one, where the challenges intensify, this demand also becomes more present [24]. This article gathers evidence on challenging experiences faced by older people who were hospitalized due to COVID-19 and positive experiences that overcame age discrimination, favoring social and health care for the elderly with positive outcomes for their health, for their relatives, and for society. 


\section{Materials and Methods}

The general aim of the study was to analyze and discuss some equity healthcare strategies that have improved the perceived health of older COVID-19 patients and which overcame multiple discrimination in access to and quality of health. The study started with the following research questions: What have been the hospital healthcare experiences of older people infected by COVID-19 during the pandemic outbreak in Spain? What elements have positively influenced the perceived health and well-being of older COVID-19 patients? To answer to this aim, an exploratory qualitative study was performed following a communicative approach. This approach was selected due to its contribution to achieving the social impact of research [25]. Research conducted under the communicative methodology promotes participants' engagement through an egalitarian dialogue with researchers together with critical analysis [26]. The use of qualitative research methods provided us with insights about the personal experiences of elderly patients who were hospitalized due to COVID-19 in a reflective manner [27]. Including the views and experiences of patients in health research contributes to identifying inefficient practices and improving efficiency, safety, and care provided. Patients' experiences should not be considered as subjective or restricted to analyze their emotional state separated from clinical work [28]. Together with a communicative approach, the present research followed a person-centered approach. A person-centered approach in health research considers people's concerns and meanings given by patients, instead of other professionals defining what is important for them. This approach includes the original experiences and needs of those directly affected by the definitions or by the healthcare received [19].

\subsection{Participants}

Participants in the study were recruited via snowball sampling. Researchers used their social networks to find suitable informants and participants in the study suggested other participants in turn. Purposive snowball sampling was selected due to its benefits for identifying participants that meet sensitive criteria, such as being affected by an illness, or for finding hard-to-reach population subgroups [29]. In the study, we included three groups of participants that followed different inclusion criteria. The first group was formed by patients over 60 admitted in hospitals due to COVID-19 and who successfully recovered. They were admitted into public or private hospitals for between one and two weeks. The interviews with this group of patients were conducted two weeks after they were discharged from the hospital, when they were at home. The second group was family members of infected elderly patients. Their family members affected by COVID-19 were admitted into public hospitals for between one and three months. The interview with Vicente, as shown in Table 1, was conducted two weeks after his father was discharged from hospital, while the interviews with Susana and Melissa were conducted while their family member was in hospital but had a good prognosis for recovery and the medical confirmation that he would be discharged soon. Both elderly patients' and relatives' views were complemented by the professional and personal reflections of nurses regarding humanized care strategies that might have contributed to improving the well-being of older patients seriously affected by COVID-19. The third group were nurses that worked directly with COVID-19 patients at different hospital settings: an Intensive Care Unit, a hospital floor, and a medicalized hospital. The stories of patients interviewed and of the family members were successful cases; they were all recovering from COVID-19. 
Table 1. Participants.

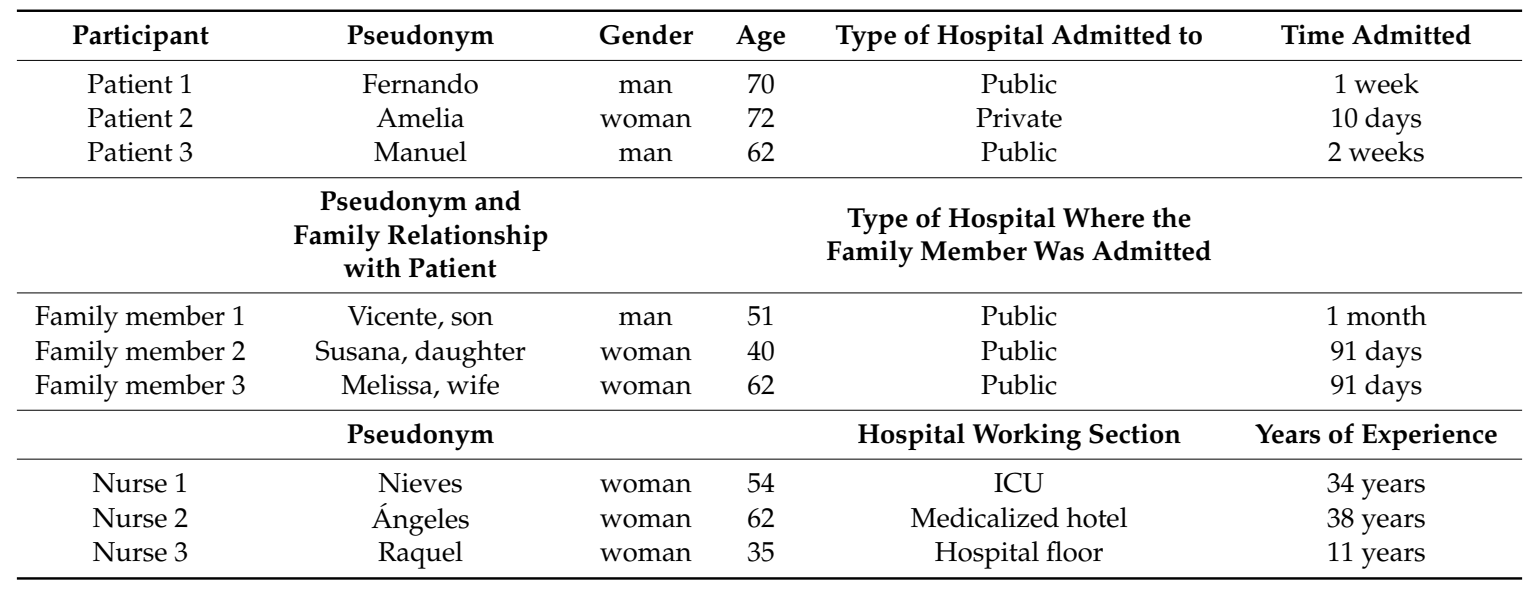

\subsection{Data Collection and Analysis}

Data were collected by conducting in-depth semi-structured interviews with a communicative approach during April, May, and June 2020. Different sources of information, three patients, three family members of other patients, and three nurses who provided information about the experiences of other patients were selected and combined to triangulate the information obtained. In-depth interviews designed for COVID-19 patients and family members were structured in three major sections. The first section covered questions about the time prior to the COVID-19 disease regarding their social habits, relationships, and general life activities and how they experienced the first illness symptoms. The questions included in the second section focused on the time of the worsening of the disease and the period of hospitalization. The questions in the last section focused on the time of discharge from the hospital and the process of recovery from the disease, for instance, "what do you think that helped you most in recovering from COVID-19?". The three sections of the interviews allowed us to obtain a linear account of the trajectory of the patients' path and the development of the illness. For each section, complementary questions were asked to find out the importance of social and family relationships throughout the process, as well as to know how they felt in each of the stages they experienced and how they perceived the care and health information they or their relatives received. Questions for the in-depth interviews with nurses focused on their professional experiences attending elderly COVID-19 patients at different health settings. We also included questions regarding the particular health and social needs of these patients, their difficulties in contrast with non-elderly patients, and the care strategies developed by them and other sanitary personnel to answer to elderly patients' needs and difficulties.

In-depth interviews were conducted in the Community of Madrid because it has been one of the most affected regions by the COVID-19 epidemic in Spain, as well as because it has been one of the regions in which unethical and non-scientific-based guidelines with controversial possible discriminatory indications have been reported. Due to the emergency measures adopted and the movement restriction established by the government in Spain, we considered it most appropriate and safest to conduct the interviews through the phone. Interviews lasted an average of forty-five minutes. They were audio-recorded, transcribed verbatim, and analyzed by the research team. Data were analyzed following a communicative approach [30]. The analysis of the information was carried out taking into consideration one main feature of the communicative methodology; the focus on the identification of both the exclusionary and transformative dimensions [31] of the reality being analyzed. The exclusionary dimension includes those interactions, thoughts, beliefs, difficulties, social barriers, among others, that prevent the transformation of said reality. The transformative dimension contains the elements and interactions that promote the overcoming of the difficulties and obstacles being faced. The identification of both exclusionary and transformative data of research constitutes a preliminary 
step for overcoming the problem investigated, thus achieving social impact [32]. The four main categories of analysis were: (1) "Family relationships", considered as the involvement and role of family members during the disease, and the impact of family or friendship interactions on the well-being of elderly patients. (2) "Actions of health personnel", referring to the information provided to elderly patients regarding their health condition, the progress of the disease, and patients' engagement in their treatment, as well as actions that overcame organizational difficulties, such as adapting guidelines or personalizing care strategies for elderly COVID-19 patients. (3) The category "Solidarity strategies" was understood as solidarity contributions among elderly patients and towards them; for instance, intergenerational solidarity, that benefit their health and others' well-being. (4) "Feelings and emotions of patients", considered as expressions and manifestations of the feelings during the different stages of their illness, such as fear, anxiety, or feeling loved and taken care of. Each category was analyzed identifying the dimensions of analysis of the communicative methodology. For instance, for the category of "Actions of health personnel", the exclusionary dimension referred to barriers to providing quality healthcare such as age discrimination. On the contrary, the transformative dimension gathered those drivers like strategies of equity healthcare that overcame barriers and acted as success stories. The interviews provided a great deal of information but in analyzing the data we focused on the four general categories of analysis to answer the main research question.

\subsection{Ethical Considerations}

Ethical approval for the study was granted by the research ethics committee of CREA Community of Research on Excellence for All. The study followed all relevant ethics procedures. Before starting the interviews, participants were informed of the aim of the study. Informed consent was obtained and signed by participants for voluntary participation. All personal data were confidential and anonymous. The interviews were coded, and pseudonyms were assigned when necessary. All older patients who participated in the study did so after recovering from their illness. They were in good physical and mental condition.

\section{Results}

\subsection{Navigating Elderly Patients' Fear and Anxiety through Medical Information and Humanized Care}

Facing the COVID-19 diagnosis and disease made many elderly patients who had no previous record of illness and their families become aware of the fragility of life. Older patients interviewed expressed that during hospitalization they sometimes felt fear, concern, or anxiety about the unknown. Amelia is an enthusiastic and spiritual 71-year-old woman who participated in the research. Initially she did not have the usual symptoms of COVID-19. However, later on, the fever increased for several days, and she had muscle pain and diarrhea. Amelia called the COVID-19 patient information phone number several times, but they repeatedly told her that it was probably just a cold and did not suggest for her to go to the nearest hospital. The fever continued rising, as well as her concern, but she did not want to go to the hospital by herself because she had heard that people over 70 who go to hospitals are ignored, and that hospitals were giving priority medical attention to young people. Structural ageism has negative consequences among elderly patients who may feel that they are a burden and not eligible for quality care.

As seen in another interviewed case, Vicente's father had bilateral pneumonia. At first, Vicente did not want to take his father to the hospital due to fear that he would be infected with other diseases and get sicker, in addition to fear that he would not be cared for well enough. Vincente's father became ill at the beginning of the pandemic when the hospitals had not yet collapsed. A fortnight after Vincente's father was admitted to the hospital, the hospitals collapsed, and his father was moved to a smaller, older, and less well-equipped hospital without giving a full explanation to the family. Then, Vicente felt that they were doing this because his father was older and because they were prioritizing the allocation of resources to other patients. Perceived discrimination increases the feeling of loneliness and anxiety 
among patients, and also in their families. It can have negative consequences, since some elderly patients wait at home until they feel worse and may receive medical treatment with delay. On the contrary, providing transparent and permanent information to elderly patients and their families contributes to making informed decisions that will impact an improvement in their health.

The daughter of a 72-year-old patient admitted to the ICU for three months due to pneumonia explained that in the first two days her father was admitted to a room and his prognosis worsened. She also explained that he had a heart disease as a previous illness. A doctor from the hospital called the family to tell them that they were evaluating whether to enter him at the ICU or not:

Susana: A doctor called us from the hospital and asked, "we are evaluating this patient and we are afraid that he is going to have to be admitted to the ICU so he is a 72-year-old man, how is his way of life? Does he have a useful life?" Useful was the word he used. The doctor also said, "Productive, does he do something productive?" ... We answered, well ..., "he is an active part of our family, he plays paddle tennis on weekends ... "You really don't know what to say because how do we value one life as useful and productive? What does useful mean for that doctor? At that moment we were afraid of what to say because then our father could have not been admitted to the ICU.

Family patients have an important role in taking a stand for their sick older family members. We frequently find that elderly patients received treatment thanks to the actions of their families. Amelia's husband took her to the community health center when her symptoms worsened. There, the doctor auscultated her and found that she had pneumonia probably caused by COVID-19. Immediately, they sent her to the nearest public hospital. When she was admitted to the hospital Amelia was alone, and for the first time in her life, she considered the possibility of not surviving the disease.

Amelia: I am an optimistic person but the first time, when I got to the hospital I thought, well, I am going in here but I don't know if I'm going to leave... The day after I arrived, they did the coronavirus test on me and it took a while to receive the result. I was worried and nervous, and I asked the nurse several times and she said that the doctor had to tell me the result of the test. So, the doctor called me that same night on the phone, but I had trouble hearing on the phone, I am partially deaf and I have hearing aids and I did not understand her well. So, since I couldn't understand her on the phone, the doctor came to see me about two or three days later and she confirmed that I had coronavirus. And then she came to see me every day and gave me explanations about my illness.

Although Amelia felt that they communicated the diagnosis with delay, each day they provided medical information about her condition. Doctors considered her hearing impairment and changed the strategy by visiting her in person. Receiving accurate and real information about their condition and the disease increased the feeling of self-control and empowerment among elderly patients.

\subsection{Including Elderly Patients' Opinion in the Medical Decisions and Treatments}

When old patients received accurate information about their health condition and the progress of the illness, they felt more confident. Treatments for COVID-19 are still novel and under experimentation. Patients' sickness progresses differently depending on several variables, such as their previous clinical condition or whether they have other diseases. Opinions and wishes of elderly patients must be respected on an equal basis with others. Fernando is a male 70-year-old patient who was admitted in a large hospital with pneumonia. He also has a chronic disease, the treatment of which attenuates the body's immune reactions. This increases Fernando's body's risk toward infections. Fernando has spent many years living with his disease every day, regulating his treatment, diet, and physical needs. After two weeks in the hospital, when he began to improve, doctors doubted whether to discharge him and send him home or transfer him to Institución Ferial de Madrid (Fair Institution of Madrid) 
(IFEMA), a field hospital with 5000 beds. Fernando was afraid that in the transfer his health would worsen, and he thought that he could be better at home because there he would be more emotionally calm, which would help him face the disease.

Fernando: The pulmonologist suggested going home or going to IFEMA. I said, let's see, I am afraid of getting worse with this change. So, what they did was finish the antibiotic treatment and that of the hydroxychloroquine and they gave me 2 days without oxygen to see how my body reacted. From there they told me that I could go home. They did so because I told them my opinion, that I saw it this way. That I was afraid because sometimes a transfer to another place can aggravate the illness. The pulmonologist was a very conscientious person. I thanked the pulmonologist for listening to me. Because there was a time when there was another digestive doctor who was evaluating the medication that I am usually following for the problem of inflammatory chronic disease and she thought about changing the medication. I was a little scared and I told her, that then we would have to change my diet, and then they said: "no, well we are going to continue the medication and that's it".

Fernando's opinion was taken into account and they kept his treatment. Like him, old patients who were able to speak and whose opinions were taken into account felt that they participated in medical decisions. This results in greater involvement and empowerment of elderly patients in their own treatment, promoting autonomy, medication compliance, and adherence to treatment.

\subsection{Transforming Individual Practices and Attitudes for Providing the Highest Attainable Standard of Health to Elderly Patients and Their Families}

At hospitals and medicalized hotels set up in Madrid during the COVID-19 health emergency, new challenges emerged for addressing the individual social needs of elderly patients and their families. Hospital personnel, and particularly nurses, had to adapt individual practices for providing quality care to old patients following a person-centered approach, even changing institutional guidelines.

Due to the saturation and lack of space in the hospitals, medicalized hotels were set up. Hotels that had adapted elevators and showers were chosen. The rooms had telephones and patients could talk to their families. In the first few weeks, patients had no basic cleaning and sanitary supplies, clothing, or resources to be entertained and to cope with the loneliness of being confined to their rooms. Thanks to the social appeal of the hotel's medical staff through social networks, they received donations from volunteers, especially young people, which favors intergenerational solidarity. The donations covered the needs of the old patients and made their stay and recovery more comfortable.

During the first weeks, some residents at the medicalized hotel were elderly patients derived from hospitals. They were admitted for at least three or four weeks. They could be disoriented because of their health condition and as a side effect of the medication. In addition, they saw nurses and doctors wearing the protective suits, glasses, and mask, and it was difficult for them to recognize who they were, which can contribute to anxiety, confusion, and mistrust. To transform these difficulties, nurses approached elderly patients making changes to the way they communicated; for instance, communicating through touch or sounds, informing them of what day and time it was, and sharing relevant news from outside. Valentina is an 85-year-old female patient who was admitted to the hospital for several weeks due to severe pneumonia caused by COVID-19. To free up space in the hospital, when her prognosis improved, she was transferred to a medicalized hotel. Valentina has been away from home for more than a month. She was partially disoriented in her hotel room, and she is visually impaired and quite deaf. Ángeles, a nurse with 35 years of experience, explained Valentina's situation:

Ángeles: The first days that we knocked on the door of her room when she opened it, Valentina was there, in her nightgown, looking scared. She looked so little and vulnerable. We were there with the protective suits and we must have looked like astronauts. From a distance, because we had to keep one or two meters away, we told her to put her finger on the 
heart rate monitor, and she reached out her arm without knowing, without understanding what that red light was and what to do. Valentina is visually impaired, she hardly ever sees, and she is also quite deaf. At first, she was very disoriented, she did not know what pills to take, she did not distinguish the pills, one day she took them all together! It was not serious, but she did not know how to do it. How did we help her? Explaining everything very well, for this we entered into her room many more times than what was established in the visiting protocol. We sat with her in bed to explain everything and guide her through the bedroom space. Valentina has now become more alert and she is taking her pills well. She is more independent, she has improved, she is now oriented in the bedroom. At first, she was lost, she couldn't see well, she didn't hear when we knocked on the door. Now she recognizes us because she already knows our voice.

Individualizing care towards elderly patients like Valentina and addressing their particular needs results in an improvement of their health and strengthens the relationship of trust between nurses and patients.

During the pandemic, nurses also dealt with emerging dilemmas regarding care towards patients and their families. They developed new strategies navigating through complex structures of the hospitals, looking for solutions to comfort patients and their families, and adjusting them to the extreme protective measures established to prevent the spread of infections. Throughout the pandemic, hospitalized patients cannot receive visits from their family members. When they die, their family members cannot attend the funeral, wake, or memorial service, nor can they bury them. Family members suffer from the progress of the illness of their loved ones from a distance and are rarely able to say goodbye properly. There is a social concern that COVID-19 patients are dying alone at hospitals. At this juncture, Nieves, a nurse who participated in the research and who has more than 30 years of experience working at the ICU of a major hospital in Madrid, decided together with other nurses that they were going to allow one family member to get into the ICU to say goodbye to their relative when they were terminal. Nurses shared their decision with the medical team and supervisors, presenting their solution with arguments defending the humanization of care. The ICU's team agreed with their proposal and organized together to make it real:

Researcher: So, are you allowing people to go to the hospitals to say goodbye to their relatives when they are not going to overcome the disease? That is very human.

Nieves: Yes, from the first moment, we said that we would do it because it was not fair. It is very hard. That you have a family member in the ICU that you cannot see, that doctors call you on the phone when they can inform you about his condition and that you may never see him again, you will never see him again! And we said that we were going to call all the relatives so they could come and say goodbye. We put a protective suit (PPE) on them to enter and say goodbye. The patient doesn't find out anything, although you never know, right? But you do it for the family. If you do not do this, you could not continue working. If you do not give yourself that minimum of humanization, I believe that I could not return to the hospital the next day.

When the healthcare provided cannot prevent older people from dying, giving the right to say goodbye to dying loved ones is an expression of quality care towards patients and families. It underpins on understanding that healthcare is not only providing medication but having an integral vision of the patients and their families' needs to take them into account. It also demonstrates that care is a social relationship that can be filled with empathy and solidarity resulting in a better outcome for society.

\subsection{Overcoming Physical Distance and Social Isolation of Elderly Patients from Hospitals}

Health and safety measures adopted to prevent the spread of COVID-19, including the restriction of movements and access to hospitals, made elderly patients having to deal with the disease away 
from their loved ones. Despite difficulties, from the first weeks of the pandemic, hospital personnel developed several initiatives aiming at facilitating patients to stay in contact with their families and friends [33]. This was particularly important for elderly patients who are impacted by the digital gap and may have more difficulties in communicating via cell phone or other electronic devices.

With the hospitalized patient cases that were unconscious, doctors have telephoned their relatives every day to inform them about the patient's condition and progress. The hospital structures have been reorganized to make these calls daily. For example, in two hospitals, the team of surgeons volunteered to make the phone calls since surgeries were interrupted. This is important because it reduces worry among the families, and they are comforted since they know how their loved ones are. When patients regain consciousness, or with patients who have been conscious during their hospitalization, the nursing staff have made it possible for them to speak to their families. They have searched for cell phones, chargers, and iPads to make it possible. They have also read emails and letters from their families to the patients, even when they were semi unconscious. For example, Melissa, the wife of a seriously ill patient admitted to the ICU, told the doctor that she was suffering because she had not had the opportunity to tell her husband that she loved him. The doctor then went to the patient and whispered in his ear that his wife loved him. Not only do the relatives of the patients benefit from knowing about the situation of their sick relatives, but it mostly benefits patients. For older patients, their main concern is knowing that their relatives are well. They need to know that their loved ones are not infected and that nothing is wrong outside. That improves their mood and reduces their worry.

When patients can maintain contact with their family members and friends, they also feel loved and feel that they matter for them, which gives them strength. Susana was in the last trimester of pregnancy when her 72-year-old father was admitted to the hospital because of COVID-19. When conducting the interview, he had been admitted to the ICU for 91 days. In this period, Susana also became infected with COVID-19 and her delivery was advanced. The newborn had to be admitted to the pediatric ICU for several days. For the family it was very distressing, especially for Susana, having her father and her newborn hospitalized. Fortunately, after a week the baby recovered, and mother and baby were released from the hospital. Susana's father still remains in the ICU, but he is awakening and regaining strength. The nurses have started making video conferences with Susana and her father. Thus, Susana's father has been able to meet his grandson for the first time. The father can barely speak, but he can hear and see his grandson everyday through videoconferences, which fills Susana and her father with hope. The first word that Susana's father wrote on a board that he uses to regain muscle tone and to communicate was his newborn grandson's name. One day he was very tired and sick; at the hospital they were not going to make the video conference because of his condition, but then he whispered his grandson's name and they made the video call. According to the experiences of nurses, helping patients to stay connected and to nurture love, friendship, and family relationships from hospitals contributes to their recovery and emotional well-being:

Researcher: Do you think it improves or influences older patients' well-being?

Nieves: Of the cases I have seen, they got very emotional, those patients who are conscious. As health providers we can do a lot but there is no one like your family. The family occupies a place that no treatment occupies. In the end, it is a matter of trust. When patients come in ICU they are usually very ill, and they put their lives in our hands. They come thinking "I'm going to the best place". They all come convinced that they are going to leave alive. But even so, the part that the family plays, many times we cannot replace it.

Researcher: And do you think it has a positive impact? Do you think that these types of conversations between patients and their relatives have encouraged them, improved their mood, which can help them better combat COVID-19?

Nieves: Sure, I have no doubt, from what I have seen, I have no doubt. We already know that under normal circumstances, imagine now, that contact with families still makes more sense. 
Being hospitalized in times of COVID-19 should not lead to social isolation. Ensuring elderly patients to be in touch with their beloved ones at a moment in which physical distance is necessary, makes them feel supported and socially included. Despite overwhelming situations and extreme measures adopted at hospitals, we find successful examples of hospital personnel that made a great effort so that older patients could be in daily contact with their families and loved ones, which was positive for their well-being.

\subsection{We All Care: Attitudes of Solidarity and Help among Elderly Patients and Towards Other Patients}

Age-related stereotypes hide the everyday valuable contributions that older persons make to society. Older persons take care of younger family members, of other dependent elderly persons, they volunteer at their communities, contribute to social cohesion and to community safety, some of them continue working and all of them contribute to the economy. Elderly patients admitted to hospitals because of COVID-19 developed social support mechanisms to improve their situation and to help those most vulnerable. During critical weeks, hundreds of patients were admitted, and emergency rooms were crowded. At times, human resources and spaces were not enough. In this extremely difficult context, some elderly patients responded by increasing solidarity and care towards other patients who were in worse conditions, even towards younger patients. Fernando, a 70-year-old patient with bilateral pneumonia due to COVID-19, spent four days in the emergency room waiting to be transferred to a hospital room. The first two and a half days he was sited in an armchair with the same street clothing. The next two days he was in a bed in the same emergency room with twenty more patients and a single bathroom. In those difficult circumstances older patients who were in better condition helped other sicker, dependent, or older patients.

Fernando: Older people were blocked; they did not know why they were there. Some had a cell phone but did not know how to use it, the older ones. There were older women alone, they were very old ... But well, we made small groups between us depending on where we were located, and we helped each other a little. We helped them to use the cell phone. It is what the body asks you to do because you realize that you are fucking sick but those over there are sicker. We collaborated with the nurses, we would say to a sick person who was in bed "put on the mask because the nurse comes to see you" and the other person answered "I do not know how to put it" and you would help him in that situation.

Older patients who took a stand and helped other patients did so in solidarity and with altruism. The type of help was diverse, from providing explanations on how to protect and prevent infections, practical information about the hospital, information from abroad, or helping them to contact their relatives. However, they also had compassionate expressions of protection towards those who were physically or emotionally weaker. Fernando, for instance, experienced a critical situation that encouraged him to react in an exemplary way for the common good of other patients. On the third day of admission to the emergency room, he realized that another patient in a nearby bed was dying. He witnessed how doctors and nurses discreetly attempted to resuscitate the patient. Fernando, despite the difficulty, remained calm and distracted another older woman giving her conversation so that she would not find out what was happening.

Fernando: there were many people with dyspnea and there was not enough space at the ICU, so many things happened. Some people died in the emergency room. Older people, huh, by respiratory blockage.

Researcher: Ugh, wow, that had to be very hard, right?

Fernando: Well yes. Seeing a person die next to you because of one of these problems ... It is very hard. But they carried it with great discretion, I found out because I saw it. It had a bed in the middle, a 75-year-old man, impressively good looking, the man was staying 
on the site and suddenly had a respiratory blockage, and that was all. But like so many, eh! People are dying! If you do not have people intubated and with other means as the ones at the ICU, then things like this happen. In a mass of patients that you cannot intubate, some die. At the time that was terrible, so terrible! You also do not know if in the other corner of the room other people know what is happening. But the one that you have next to you or in a bed beyond, you notice and realize. Although doctors dealt with this case with great discretion. They did many things but no, he could not survive ... they carried it with tremendous discretion.

E: After it happened, did they explain it to you in some way, could you talk to someone about what happened if you needed to?

Fernando: No, no, no ... the only thing you can do at that time is keep quiet because there were many older people. Look, there was an older person, a black Latin American woman who was with a tremendous funk. She was next to the man who was dying, they sat her in the same armchair in which I had been in those two and a half days. And she told me 'look at that man ...' And I pretended not to know what was happening and I changed the conversation ... The poor woman was completely alone. She gave me the impression that she was an illegal immigrant who had no one or nothing. I think that you have to act responsibly because there are many people that will not understand it, they would be much more alarmed.

For older patients that cared for other patients, helping others made themselves feel useful and raised their spirits. Moreover, they believed that in case they would need it, they would find the same aid from others who would care for them. Elderly patients that could help other patients felt included and useful. Chronological age should never be an indicator of the potential contributions that someone can make to society. Older people are active and valued members of our society, and they have also been active in the hardest times that hospitals have experienced during the pandemic.

\section{Discussion and Conclusions}

In this study, we explored some experiences of older people who were hospitalized due to COVID-19 during the pandemic outbreak in the Community of Madrid, Spain. We were also able to identify several elements that have positively influenced the perceived health and well-being of elderly COVID-19 hospitalized patients. Overall, this study raised remarkable examples of practices, interactions, and procedures at healthcare settings of equity care that challenged age discrimination, resulting in humanized care that contributed to their recovery and to the well-being of their families. Findings show the importance of considering elderly patients' opinions and promoting patient engagement on their own health, as well as the significance of care recipients' and caregivers' relationships. Previous studies have shown that receiving supportive information from healthcare providers contributes to improving older patients' health [18]. The evidence gathered in this paper shows that older patients care for other patients and even for younger patients developing strategies of solidarity. This finding can reinforce the argument that elderly people continue making remarkable contributions even at difficult moments and that they deserve to be cared for with the highest attainable health standard. The social support mechanisms and solidarity actions developed among elderly patients analyzed in this paper may indicate the prominence of interpersonal relationships and the fact that care is a social relationship that can be cultivated. Moreover, results show the important role of family relationships in elderly COVID-19 patients' paths. Previous studies have found that elderly patients do not always receive the care that they deserve at hospitals and that having visitors is associated with reduced odds of receiving negative interactions [15]. In the cases analyzed in this study, we also identified that families have a crucial role and implication in the well-being of their elders affected by COVID-19. For elderly COVID-19 hospitalized patients, being in contact 
with their families made them feel involved in the daily life and in the family milestones, which, according to the testimonies gathered, contributed to their perceived recovery. Previous studies highlight the value that older patients give when they feel that they are being cared for if they need to, which increases their sense of security and social belonging, creating a supportive context with positive social relationships [34].

International organizations and groups of experts have raised attention on the impact of ageism since the COVID-19 epidemic started. They have published different works on the risks of discrimination against the elderly, which can have negative consequences, from miscounting the number of deaths of the elderly to the social devaluation of older adults [23]. One of the strengths of this paper is that it provides in-depth information through the direct testimonies and voices of elderly COVID-19 patients, their families, and sanitary personnel. This exploratory research contributes to shedding light on a part of the dramatic reality experienced in the Community of Madrid in the harshest months of the pandemic. For this paper, we have been able to gather testimonies on a very sensitive issue and in a difficult context to carry out sociological fieldwork. The findings gathered in this paper should be considered in light of some limitations. Regarding materials and methods, due to the sensitive topic of research and the period when it was conducted, we have limited access to data and to find participants that met the selection criteria. Another limitation is related to the self-reported data of participants. The events and testimonies analyzed in the paper relied on the experiences remembered by participants, their interpretation, understanding, and attribution of episodes. In this sense, the time between the moment when elderly patients leave the hospital and when the interview was done might have influenced the perception of interviewees and the recalling of events. Lastly, data collection focused on the Community of Madrid because we were particularly interested in this region. Therefore, data obtained and analyzed might not be transferred or understood in other particular contexts, regions, or countries. Future research should overcome these limitations using alternative methodologies and by expanding the number of participants. Although this study delves into the cases of a group particularly vulnerable to suffering social and health discrimination, further research is needed on the cases of older people infected by COVID-19 who have not yet been hospitalized and, importantly, on elderly people that were at nursing homes during the pandemic.

In one of the central floors of a hospital, the nurses built a giant mural of hearts with the names of the patients that overcame COVID-19 written in the hearts. It is a message of homage, creation of meaning, and hope for the hospital community and for society. At the most critical and terrifying moments of the pandemic, positive and hopeful examples emerged from the solidarity and care of people and communities overcoming discrimination in healthcare and envisioning better measures to defeat the pandemic without leaving elderly people behind. Achieving health equity is among the Sustainable Development Goals (2030). International initiatives, such as the one launched by the Sant'Egidio Community (https://www.santegidio.org/pageID/37740/langID/en/THERE-IS-NO-FUTURE-WITHOUT-THEELDERLY-INTERNATIONAL-APPEAL-TO-REHUMANIZE-OUR-SOCIETIES-AGAINST.html), are appealing to re-humanize our societies because there is no future without the elderly and against a selective healthcare system, and contribute to overcoming age discrimination. When older people receive humanized and quality healthcare, we find success stories, such as the ones gathered in this research, that make us a more just and supportive society, impacting on the common good of all. Despite unethical and non-scientific-based guidelines and social discourses that reproduce multiple discrimination, bias, and inequalities in healthcare against elderly people, it is possible to progress towards quality health for all, even in the age of the COVID-19 pandemic.

Author Contributions: Conceptualization, A.A., G.M., and M.R.-S.; methodology A.A., G.M., and M.R.-S.; data collection G.M. and D.V., data analysis, A.A., D.V., G.M. and M.R.-S.; writing-original draft preparation, A.A., D.V., G.M. and M.R.-S.; writing-review and editing, A.A., D.V., G.M. and M.R.-S. All authors have read and agreed to the published version of the manuscript.

Funding: This research received no external funding. 
Acknowledgments: We would like to thank participants in this research, especially to patients and family of patients affected by COVID-19. Thank you also to the testimony of nurses who inspired this study, for their courage, dedication, and great work during the pandemic.

Conflicts of Interest: The authors declare no conflict of interest.

\section{References}

1. Instituto de Salud Carlos III 2020. Report on the Situation of COVID-19 in Spain COVID-19. Report No. 29. 7 May 2020. Available online: https://www.isciii.es/QueHacemos/Servicios/VigilanciaSaludPublicaRENAVE/ EnfermedadesTransmisibles/Documents/INFORMES/Informes\%20COVID-19/Informe\%20n\%C2\%BA\% 2029.\%20Situaci\%C3\%B3n\%20de\%20COVID-19\%20en\%20Espa\%C3\%B1a\%20a\%2007\%20de \%20mayo \% 20de\%202020.pdf (accessed on 23 May 2020).

2. Pulido, C.; Ruíz-Eugenio, L.; Redondo-Sama, G.; Villarejo-Carballido, B. A new application of SISM for overcoming fake news in Health. Int. J. Environ. Res. Public Health 2020, 7, 2430. [CrossRef] [PubMed]

3. Huchet, E.; Georgantzi, N. Ageism in The Age of Covid-19. Opinion for Each Other. 2020. Available online: https://eachother.org.uk/ageism-in-the-age-of-covid-19/ (accessed on 5 June 2020).

4. Cesari, M.; Proietti, M. COVID-19 in Italy: Ageism and Decision Making in a Pandemic. J. Post Acute Long Term Care Med. 2020, 21, 576-577. Available online: https://www.jamda.com/article/S1525-8610(20)30284-X/fulltext (accessed on 5 June 2020). [CrossRef] [PubMed]

5. Hall, N. The Digital Party: Political Organisation and Online Democracy. Int. Sociol. 2019, 34, $624-628$. [CrossRef]

6. Farrell, T.W.; Francis, L.; Brown, T.; Ferrante, L.E.; Widera, E.; Rhodes, R.; Rosen, T.; Hwang, U.; Witt, L.J.; Thothala, N.; et al. Rationing Limited Healthcare Resources in the COVID-19 Era and Beyond: Ethical Considerations Regarding Older Adults. J. Am. Geriat. Soc. 2020, 68, 1143-1149. [CrossRef] [PubMed]

7. Ely Yamin, A.; Habibi, R. Human Rights and Coronavirus: What's at Stake for Truth, Trust and Democracy? Health Hum. Rights J. 2020. Available online: https://www.hhrjournal.org/2020/03/human-rights-andcoronavirus-whats-at-stake-for-truth-trust-and-democracy/ (accessed on 20 April 2020).

8. World Health Organization (WHO). Health Equity. 2017. Available online: https://www.who.int/topics/ health_equity/en/ (accessed on 5 June 2020).

9. AGE Platform Europe. COVID-19 and Human Rights Concerns for Older Persons. 2020. Available online: https://www.age-platform.eu/publications/covid-19-and-human-rights-concerns-older-persons (accessed on 5 June 2020).

10. Office of the High Commissioner for Human Rights (OHCHR). No Exceptions with COVID-19: "Everyone Has the Right to Life-Saving Interventions"-UN Experts Say. 2020. Available online: https://www.ohchr. org/EN/NewsEvents/Pages/DisplayNews.aspx?NewsID=25746\&LangID=E (accessed on 5 June 2020).

11. Office of the High Commissioner for Human Rights (OHCHR). "Unacceptable" - UN Expert Urges Better Protection of Older Persons Facing the Highest Risk of the COVID-19 Pandemic. 2020. Available online: https://www.ohchr.org/EN/NewsEvents/Pages/DisplayNews.aspx?NewsID=25748\&LangID=E (accessed on 5 June 2020).

12. Chang, E.-S.; Kannoth, S.; Levy, S.; Wang, S.-Y.; Lee, J.E.; Levy, B.R. Global reach of ageism on older persons' health: A systematic review. PLoS ONE 2020, 15, e0220857. [CrossRef] [PubMed]

13. Jackson, S.E.; Hackett, R.A.; Steptoe, A. Associations between age discrimination and health and wellbeing: Cross-sectional and prospective analysis of the English Longitudinal Study of Ageing. Lancet 2019, 4, E200-E208. [CrossRef]

14. Levy, B.R.; Slade, M.D.; Chung, P.H.; Wang, S. Ageism Amplifies Cost and Prevalence of Health Conditions. Gerontologist 2020, 60, 174-181. [CrossRef]

15. Bridges, J.; Frankland, J.; Griffiths, P.; Libberton, P.; May, C. Coordinating Compassionate Care Across Nursing Teams: The Implementation Journey of a Planned Intervention. In Transitions and Boundaries in the Coordination and Reform of Health Services, Organizational Behaviour in Healthcare; Nugus, P., Rodríguez, C., Denis, J.-L., Chênevert, D., Eds.; Palgrave Mcmillian: London, UK, 2020. [CrossRef]

16. Barker, H.R.; Griffits, P.; Mesa-Eguiagaray, I.; Pickering, R.; Gould, L.; Bridges, J. Quantity and quality of interaction between staff and older patients in UK hospital wards: A descriptive study. Int. J. Nurs. Stud. 2016, 62, 100-107. [CrossRef] 
17. Bridges, J.; Flatley, M.; Meyer, J. Older people's and relatives' experiences in acute care settings: Systematic review and synthesis of qualitative studies. Int. J. Nurs. Stud. 2010, 47, 89-107. [CrossRef]

18. Ito, M. Patient-centered care. In Fundamentals of Telemedicine and Telehatlh; Gogia, S., Ed.; Elsevier: Amsterdam, The Netherlands, 2019; pp. 115-126. [CrossRef]

19. Boggatz, T. Quality of Life and Person-Centered Care for Older People; Springer: Cham, Switzerland, 2020. [CrossRef]

20. United Nations Development Programme (UNDP). COVID-19 Pandemic. Humanity Needs Leadership and Solidarity to Defeat the Coronavirus. 2020. Available online: https://www.undp.org/content/undp/en/home/ coronavirus.html (accessed on 5 June 2020).

21. Piccoli, B.G. Hospitals as health factories and the coronavirus epidemic. J. Nephrol. 2020, 33, $189-191$. [CrossRef]

22. Klein, A. COVID-19: Los Adultos Mayores entre la "Revolución" Gerontológica y la "Expiación" Gerontológica. Res. Ageing Soc. Policy 2020, 8, 120-141. [CrossRef]

23. Fraser, S.; Lagacé, M.; Bongué, B.; Ndeye, N.; Guyot, J.; Bechard, L.; Garcia, L.; Taler, V.; CCNA Social Inclusion and Stigma Working Group; Adam, S.; et al. Ageism and COVID-19: What does our society's response say about us? Age Ageing 2020, afaa097. [CrossRef] [PubMed]

24. Aiello, E.; Donovan, C.; Duque, E.; Fabrizio, S.; Flecha, R.; Holm, P.; Molina, S.; Oliver, E.; Reale, E. Effective strategies that enhance the social impact of social sciences and humanities research. Evid. Policy J. Res. Debate Pract. 2020, 1-16. [CrossRef]

25. Flecha, R.; Soler-Gallart, M.; Sordé, T. Social impact: Europe must fund social sciences. Nature 2015, 528, 193. [CrossRef] [PubMed]

26. Soler-Gallart, M. Achieving Social Impact: Sociology in the Public Sphere; Springer: Cham, Switzerland, 2017.

27. Denzin, N.K.; Lincoln, Y.S. The SAGE Handbook of Qualitative Research, 4th ed.; SAGE: Los Angeles, CA, USA, 2011.

28. Doyle, C.; Lennox, L.; Bell, D.A. Systematic review of evidence on the links between patient experience and clinical safety and effectiveness. BMJ Open 2013, 3, e001570. [CrossRef] [PubMed]

29. Sadler, G.R.; Lee, H.-C.; Lim, R.S.-H.; Fullerton, J. Research Article: Recruitment of hard-to-reach population subgroups via adaptations of the snowball sampling strategy. Nurs. Health Sci. 2010, 12, 369-374. [CrossRef]

30. Gómez, A.; Padrós, M.; Ríos, O.; Mara, L.C.; Pukepuke, T. Reaching Social Impact through Communicative Methodology. Researching with Rather than on Vulnerable Populations: The Roma Case. Front. Educ. 2019, 4. [CrossRef]

31. Gómez, A.; Elboj, C.; Capllonch, M. Beyond action research: The communicative methodology of research. Int. Rev. Qual. Res. 2013, 6, 183-197. [CrossRef]

32. Sordé Martí, T.; Flecha, R.; Rodríguez, J.A.; Bosch, J.L.C. Qualitative Inquiry: A Key Element for Assessing the Social Impact of Research. Qual. Inq. 2020. [CrossRef]

33. Almeida, F. The concept of Human2Human in The Response to COVID-19. Int. Multidiscip. J. Soc. Sci. 2020, 9, 23-45. [CrossRef]

34. Lui, C.-W.; Everingham, J.-A.; Warburton, J.; Cuthill, M.; Bartlett, H. What makes a community age-friendly: A review of international literature. Australas. J. Ageing 2009, 28, 116-121. [CrossRef] [PubMed]

(C) 2020 by the authors. Licensee MDPI, Basel, Switzerland. This article is an open access article distributed under the terms and conditions of the Creative Commons Attribution (CC BY) license (http://creativecommons.org/licenses/by/4.0/). 